\title{
RESERVOIR CHARACTERIZATION BY CROSSHOLE SEISMIC IMAGING
}

\author{
M. Nafi Toksöz, Principal Investigator \\ Roger M. Turpening, Co-Principal Investigator \\ Earth Resources Laboratory \\ Department of Earth, Atmospheric, and Planetary Sciences \\ Massachusetts Institute of 'Technology \\ Cambridge, Massachusetts 02139 \\ DOE Report Number - DOE/ER/14084-3 \\ DOE Contract Number - DOE-FG02-89ERI4084
}

10 June 1992

\section{DISCLAIMER}

\begin{abstract}
This report was prepared as an account of work sponsored by an agency of the United States Government. Neither the United States Government nor any agency thereof, nor any of their employees, makes any warranty, express or implied, or assumes any legal liability or responsibility for the accuracy, completeness, or usefulness of any information, apparatus, product, or process disclosed, or represents that its use would not infringe privately owned rights. Reference herein to any specific commercial product, process, or service by trade name, trademark, manufacturer, or otherwise does not necessarily constitute or imply its endorsement, recommendation, or favoring by the United States Government or any agency thereof. The views and opinions of authors expressed herein do not necessarily state or reflect those of the United States Government or any agency thereof.
\end{abstract}

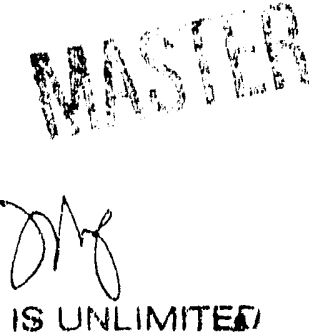




\title{
RESERVOIR CHARACTERIZATION \\ B Y \\ CROSS HOLE MEASUREMENTS
}

\author{
SEMI-ANNUAL PROGRESS REPORT \\ Roger Turpening \\ Earth Resources Laboratory \\ Massachusetts Institute of Technology \\ Cambridge, Massachusetts
}

\section{BACKGROUND}

The Earth Resources Laboratory (ERL) at the Massachusetts Institute of Technology (MIT) has completed two and one half years of a four year research effort. This program of investigation in conjunction with the companion effort at the Sandia National Laboratories is focused on the field use of cross hole measurements in reservoir characterization. ERL through its industrial support has a research facility in the Northern Michigan Reef Trend. Deep (6,500 ft.) holes have been placed on opposite sides $(2,000 \mathrm{ft}$. apart) of a producing reef. Since the holes are much deeper (see Figure 1) than the reservoir (at 4,700 ft.) they provide an opportunity better than that usually folnd in industry for the use of cross hole techniques.

The original plan for the four year effort was stated as follows:

Year One--Preparation

Year Two--Use of vertically polarized shear waves (SV)

Year Three--Addition of horizontally polarized shear waves (SH)

Year Four--Present static image of reservoir properties and

--Observe time varying phenomena in the reservoir by reshooting high frequency compressional (P) survey

This report covers the first six months of the third year. The major accomplishment during that period has been the obser'ation of clear SV signals from the Sandia source over a distance of $1,900 \mathrm{t}$. 


\section{Data Acquisition}

The geologic column at the ERL's Research Facility typical of the Michigan Basin. Limestones, dolomites, salts, and calcareous shales are found over all depth irtervals. The Silurian reefs are the hydrocarbon reservoirs here and they occur on the Grey Niagaran limestone. The data acquisition plan was to deploy the Sandia source and the Halliburton Logging Services array at shallow depth firsi and then to proceed down to the depth of the reservoir. For reasons that will be discussed later, the source did not perform at depths greater than approximately $1600 \mathrm{ft}$. and therefore the available time, which was already short, was spent at these shallow depths. Figures 1 and 2 show cross sections of the Research Facility. The levels of deployment for both the source (950 ft. down to $1,600 \mathrm{ft}$. in $50 \mathrm{ft}$. intervals) and receivers (sondes at 1,300, 1,325, and 1,350 ft.) are given in each figure. The first figure displays the engineering details of our boreholes while the second figure shows the borehole geometry. Notice that the source positions occupy a region of slight borehole deviation. Extensive use of gyroscope surveys in both of our holes gives us the location of these holes in three dimensional space.

The figures show that the three component receivers were positioned in the Traverse Limestone (S wave velocity of approximately 9,100 ft./sec.) while the source moved from the Antrim Shale ( $S$ wave velocity of approximately 5,500 ft./sec.) to the Traverse Formation ( $\mathrm{S}$ wave velocity of approximately $8,000 \mathrm{ft} . / \mathrm{sec}$.) and into the Traverse Limestone. Our boreholes are approximately $1,910 \mathrm{ft}$. apart at these depths.

Televiewer data and our nine-component, zero-offset VSP data both indicate that this Intire interval is fractured with near vertical fractures. Thus orthorhombic anisotropy should be expected in the Antrim Shale and azimuthal anisotropy should be anticipated in the Traverse Formation and Traverse Limestone. Although seismic attenuation is expected to be low in these very hard formations the fractures will increase the apparent attenuation.

\section{Data}

Figures 3 and 4 display the data obtained on one vertical component and one horizontal geophone. Eight, four second sweeps were stacked in each. case. Weak. P waves can be seen on the horizontal geophone in Figure 4 at levels commensurate with traditional radiation patterns.

The spectrum of the sweep (when the source was at the $1,400 \mathrm{ft}$. level) is shown in Figure 5. Note that usable signal power exists only out to about $140 \mathrm{~Hz}$. This also evident in the spectra of the SV arrivals themselves. 
Obviously the signal to noise ratio is best when the seismic wave propagation is confined to the Traverse Limestone. When the signals must cut across interfaces energy is lost. In these plots the noise level seems to rise as the signal levels decrease but this is only a result of the fact that each trace is independently gained to meet individual trace maxima. Although these signals are not strong and source improvements must be made these results are encouraging since no signal at all was expected over these distance ranges.

Figures 6 and 7 display the spectra of two different SV signals. In figure 6 the signal has propagated $1,940 \mathrm{ft}$. The result is a narrow band signal having less than one octave of bandwidth. In Figure 7 the source is in the Traverse Limestone along with the receiver. The propagation distance is nearly the same $(1,900 \mathrm{ft}$.) but a much broader spectrum of two octaves occurs. Preliminary examination of the data from the 3,000 ft.. level in these boreholes shows no signal at all.

\section{Source Resonance}

Although one could easily explain a loss of high frequency energy by postulating lower Q's in the Antrim Shale this does not explain the apparent loss of the low side of the spectrum when the source is at a shallower depth. This observation highlights a question that will be examined in detail this year. The question is "what is the behavior of the sweep as a function of depth?"

Recall that this source was designed to operate around a natural resonance of its mechanical system, in fact it derived much of its power from that resonance. As the source is deployed at deeper and deeper levels it appears that the resorlance is first damped and then lost entirely (see the 1,600 ft. data in Figure 1). This is the first observation of this phenomena and that is not surprising since all previous tests of this source were done at depths less than 1,000 ft. Since this is the only downhole SV source in the world that can be deployed in a fluid filled borehole it is important to understand this problem and engineer a solution.

\section{Future Work}

Given the modest success of this source and the fact that it is the only SV source that can operate in a fluid filled borehole it is important to improve this source for future work. The resonance peak should be suppressed but not to the point of complete signal extinction. Modifications to the tool done in past to speedup data acquisition may have to undone and new solutions found. Hopefully this engineering can be done in time for the summer 1993 field period at MIT's Research Facility. With these 
modifications we should be able to work at the depth of the hydrocarbon reservoir and thus achieve the goals outlined in the statement of work, albeit one year behind schedule. The technology for the reillumination of the reservoir with $\mathrm{P}$ waves is at hand and can be performed at any time.

\section{Summary}

The Sandia downhole vertical vibrator was tested in September 1991 at depths and over interwell distances never attempted, by this source, before. It was known at the outset that time and funding constraints precluded the collection of a full tomographic data set. The usual field difficulties reduced the time even further however reasonable shear wave (SV) signals were obtained at depths greater than previously attempted. This success together with modifications to the source by Sandia and/or contractors to Sandia will allow us to operate the Sandia source at and below the depth of the hydrocarbon reservoir in 1993. This would allow the statement of work to be met. The reillumination of the reservoir with $P$ waves, to detect any time varying changes, can be done at any time. 
N W

\section{EARTH RESOURCES LABORATORY \\ RESERVOIR DELINEATION \\ RESEARCH FACILITY}

SE

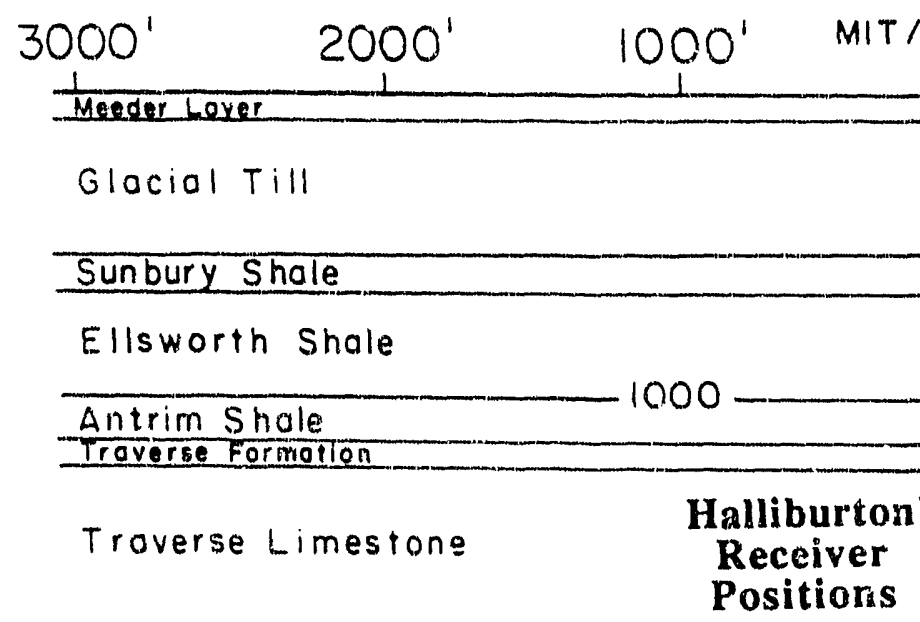

Bell shale

Dundee Limestone

Tread cily voremile

Reed City Dolomite
Dalt Stringers
Detrolt Solt

Detroit River Anhyd -ite

("The Massive" Anhydrite)

Amherstburg Dolomite

Bois Blanc Dolomite

Bass Island Dolomite

\begin{tabular}{l} 
F Solt I \\
Stringer in F Soll \\
\hline EUnit Shale \\
\hline EShale \\
\hline B Sali Stringers in C Shole?
\end{tabular}

Solino shole

A2 Carbonato

4563

\section{A? Soll}

Gray Niagoran

Schoolcroft Carbonote

Al Salt

3446

Burnt Bluff Carbonate

Eabor hend shate

Encinoulion Shate

Cincinnation Carbonate

Utico Shole

Trenton Limestone

Black River Limestone

Prairie du Chien Standstone

$-5531$

$-5925$
$-6300$ $-6450$
1788

Reed Cify Dolomito

2835

3045

$4950-$ Al Evaporite

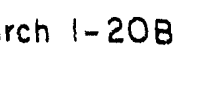

MIT/Siech I- 2IA $2000^{\prime}$

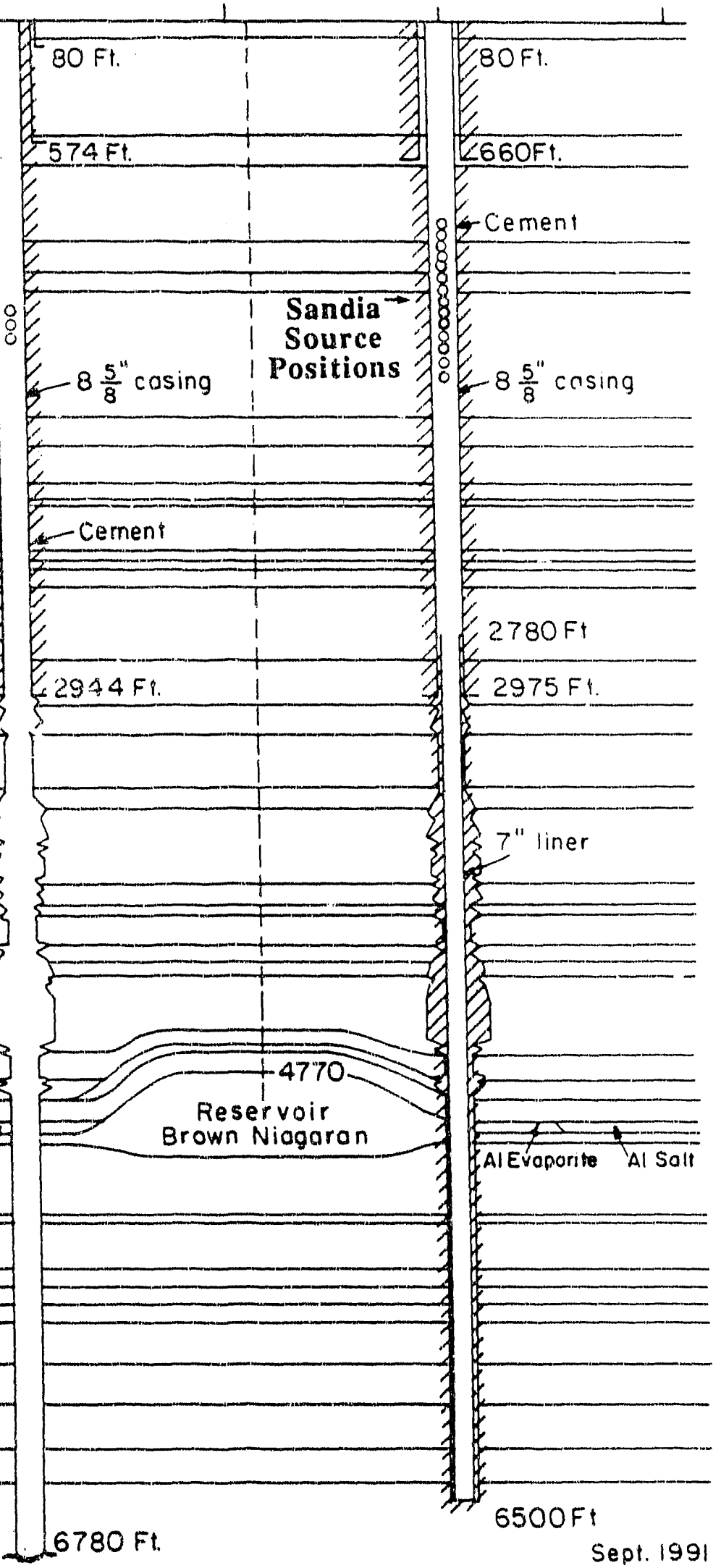

Feet Depth

Figure 1. Location of source and receiver positions. Porehole engincesing is shown. 


\section{EARTH RESOURCES LABORATORY \\ RESERVOIR DELINEATION \\ RESEARCH FACILITY}

NW

\section{0 \\ Meder Layer \\ Glacial Till \\ Sunbury Shale \\ Ellsworth Shole}

$2000^{\prime}$

Antrim Shale

Traverse Limestnne

Bell Shale

Dundee Limestone

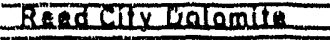

Reed City Dolomite

Detrell Rluer Salt

Detroit River Anhydrite

("The Massive" Anhydrite)

Amnerstburg Dolomite

Bois Blanc Dolomite

Boss Islond Dolomite

Saling shole

F Salt 1

Stringer in F sall

EUnit Shale
CSshale

B Solt

A2 Corbonate

A Soll

Al corbenote

Gray Niogaran Al Soly

Schoolcroff Carbonore

Burnt Bluff Carbonote

Tabor Heac Shat

Mapleullin Dolomits

Cincinnotion Shale

Cincinnotion Corbonate

Utica Shale

Trenton Limestone

Black River Limestone

Proirie du Chien Stonds tone

$1000^{\prime}$

1000

1788

Solf Stringers

Detroit Solt

2835

$-3045$

4563

4950

$-5925$

5531

MIT / Burch !- 2OB

Halliburton

Receiver

Positions

$-$

MIT/Stech I- 21A

SE

$2000^{\prime} \quad 3000^{\prime}$

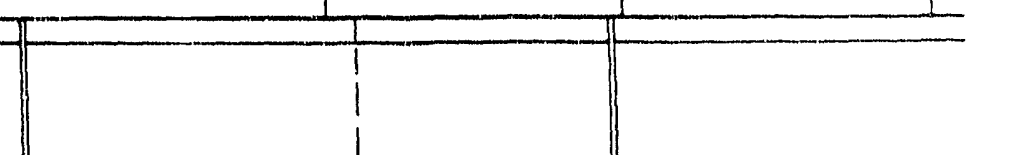

$\frac{\text { Recers }}{\text { Solf }}$

-

$\frac{1}{1}=-2$

-Sandia

Source

Positions

Al Evaporito

Reservoir

Brown Niagaran
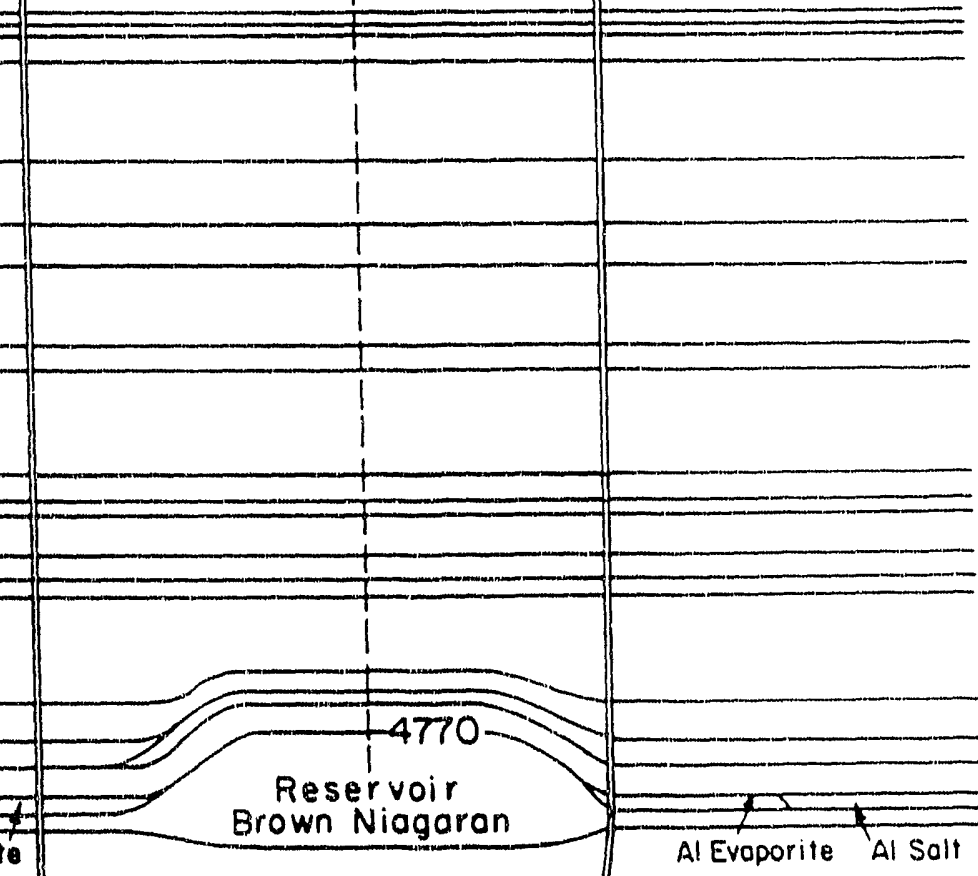


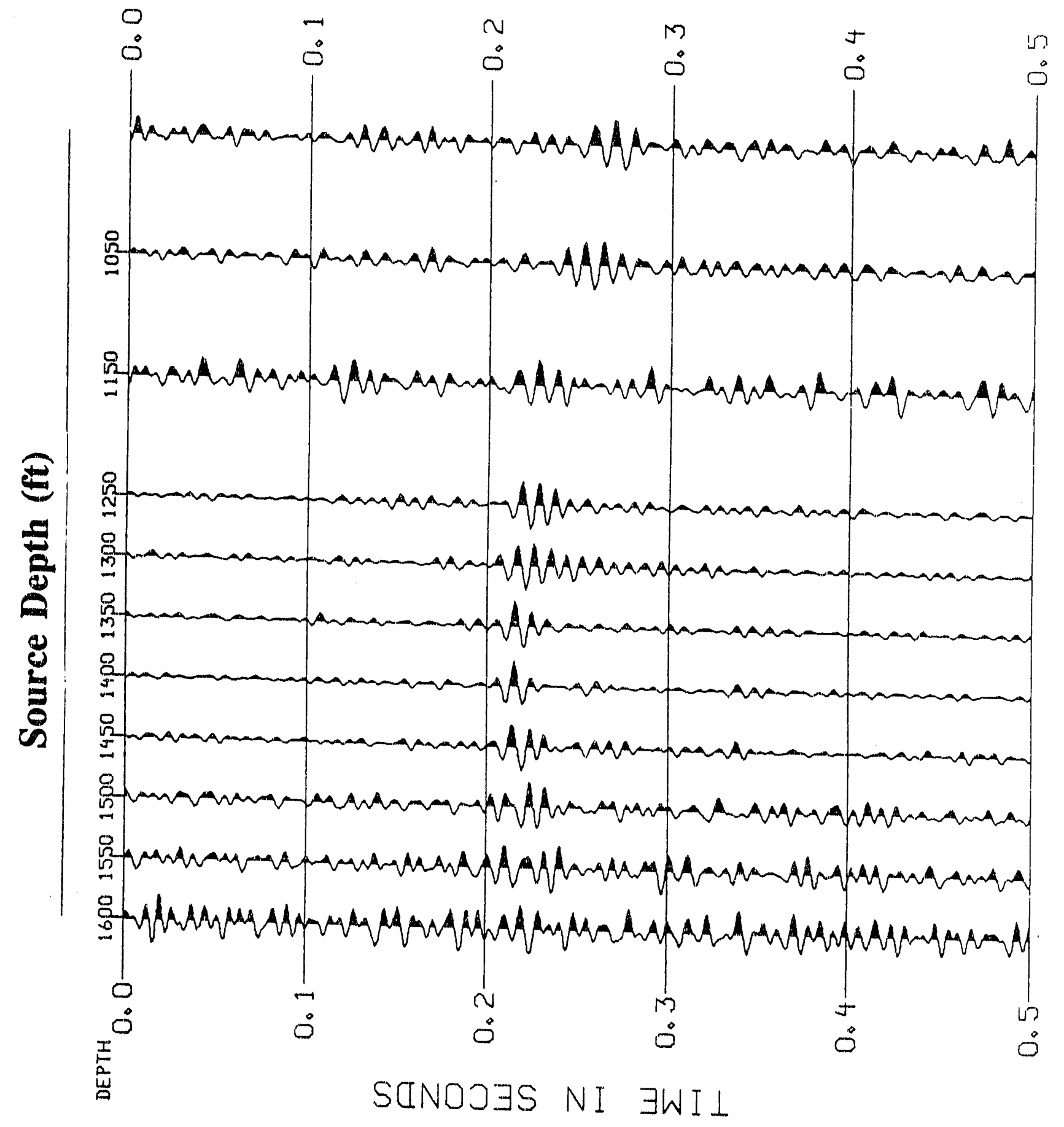

Figure 3. SV signals on the vertical component geophone at a depth of $1300 \mathrm{ft}$. Each trace
is individually scaled. 


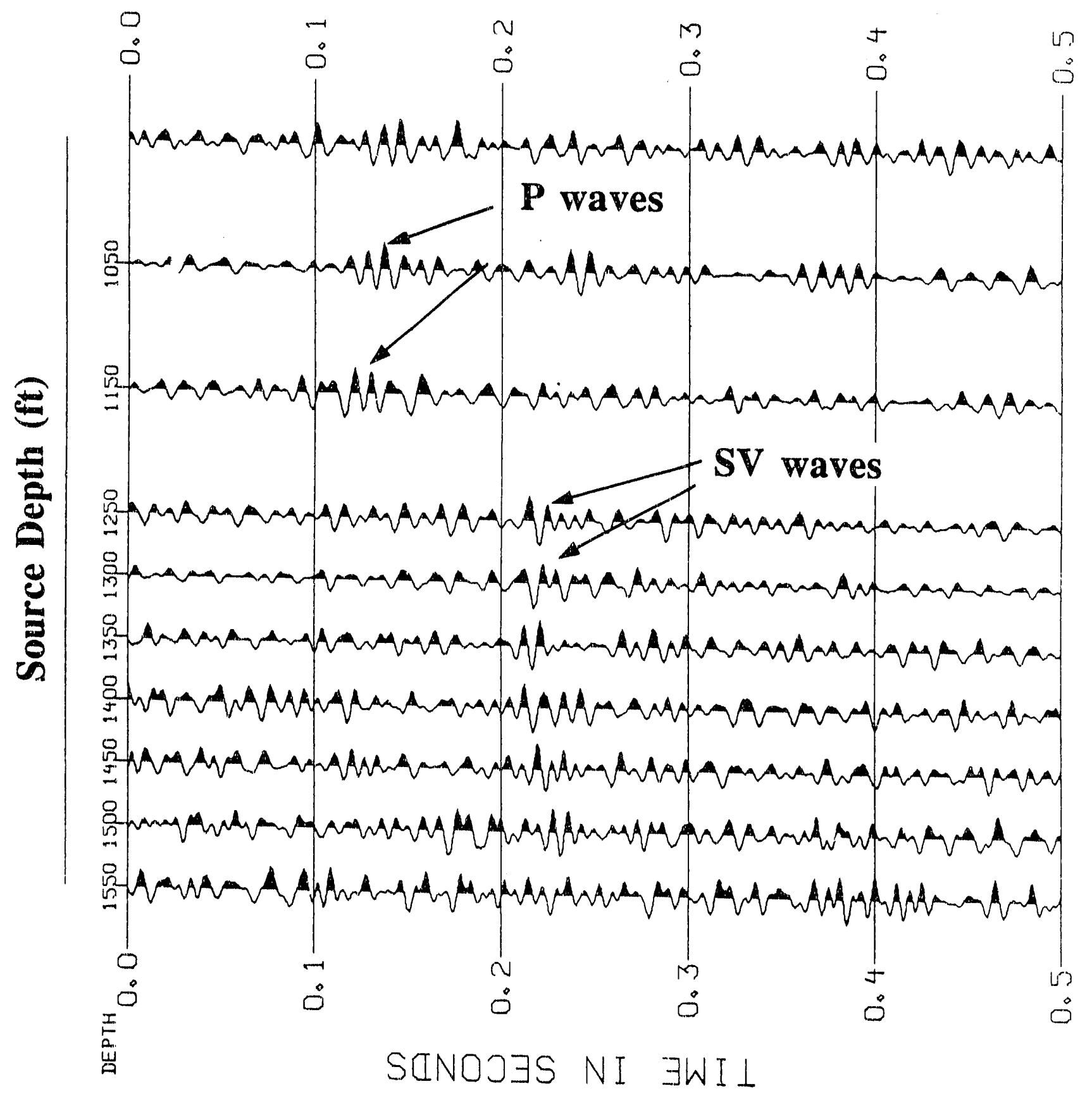

Figure 4. SV and P wave signals on one, non -otated horizontal geophone in the upper
most sonde (1300 ft.) 


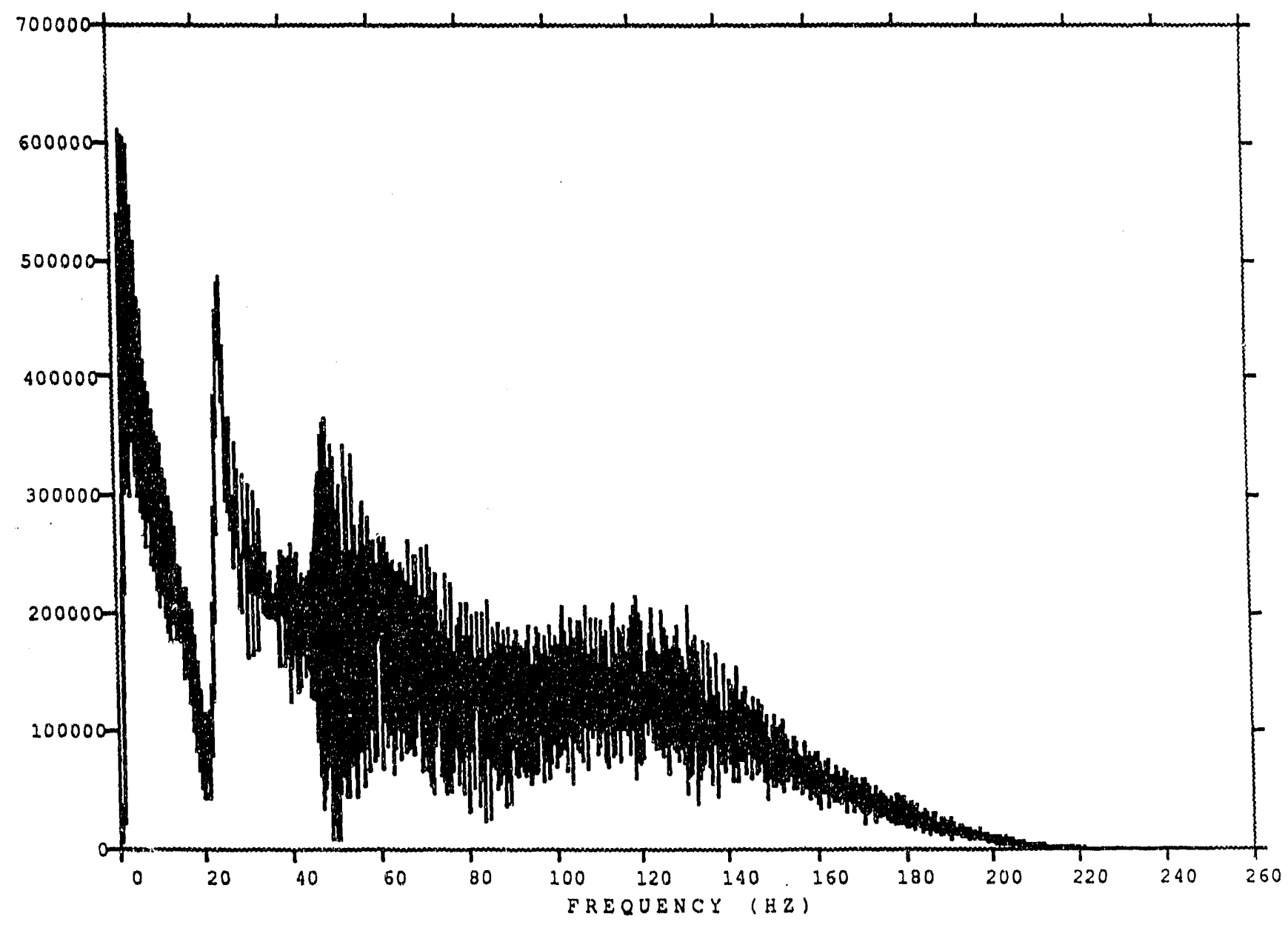

Figure 5. Spectrum of raw sweep of Sandia source when the sonde was at a depth of 1400 $f t$. 


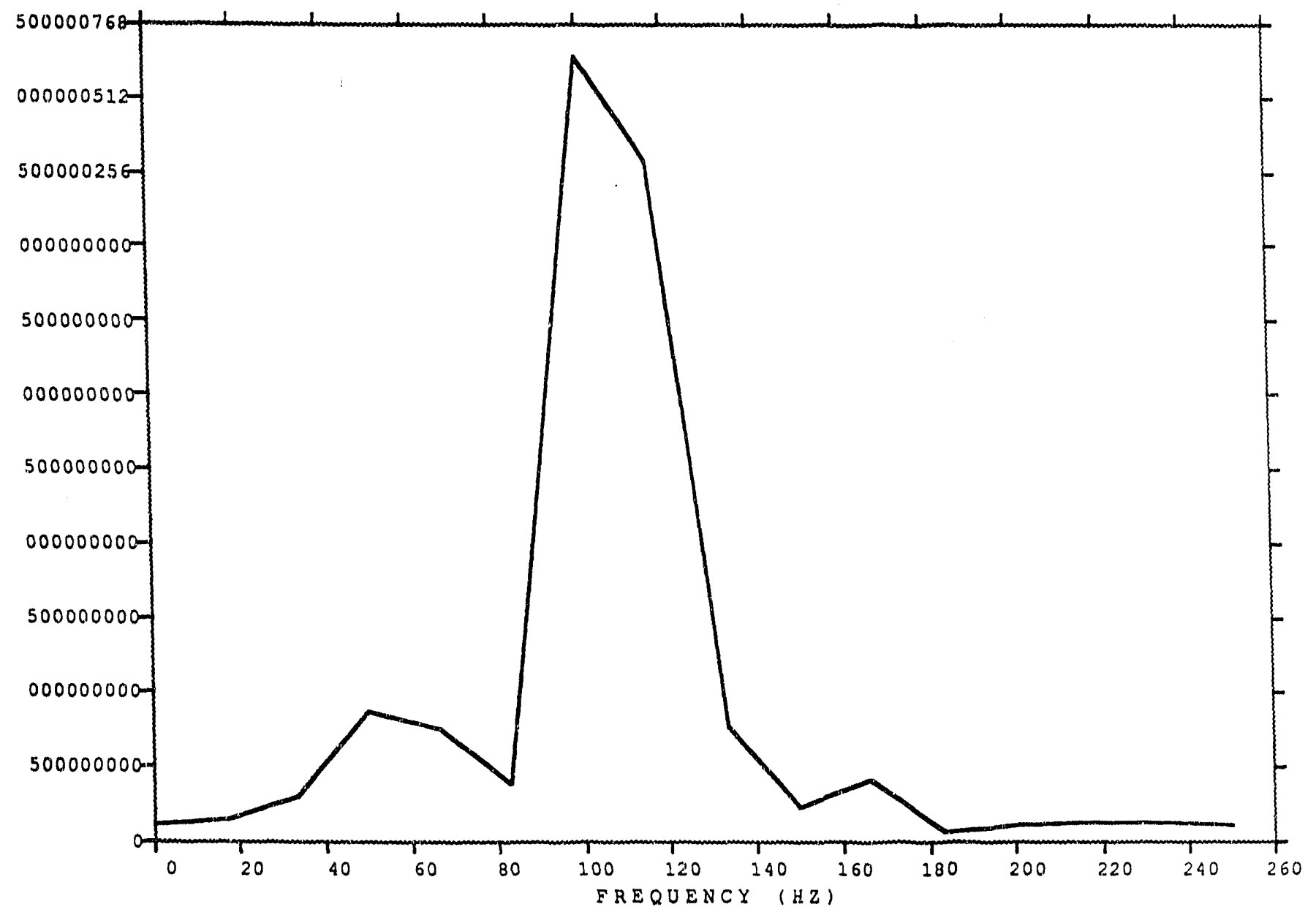

Figure 6. Spectrum of shear wave (SV) wavelet on a vertical component geophone, when the Sandia source was at the $1050 \mathrm{ft}$ level. The receiver is the upper most sonde (1300 ft) in the Halliburton artay. Total path length is $1940 \mathrm{ft}$. 


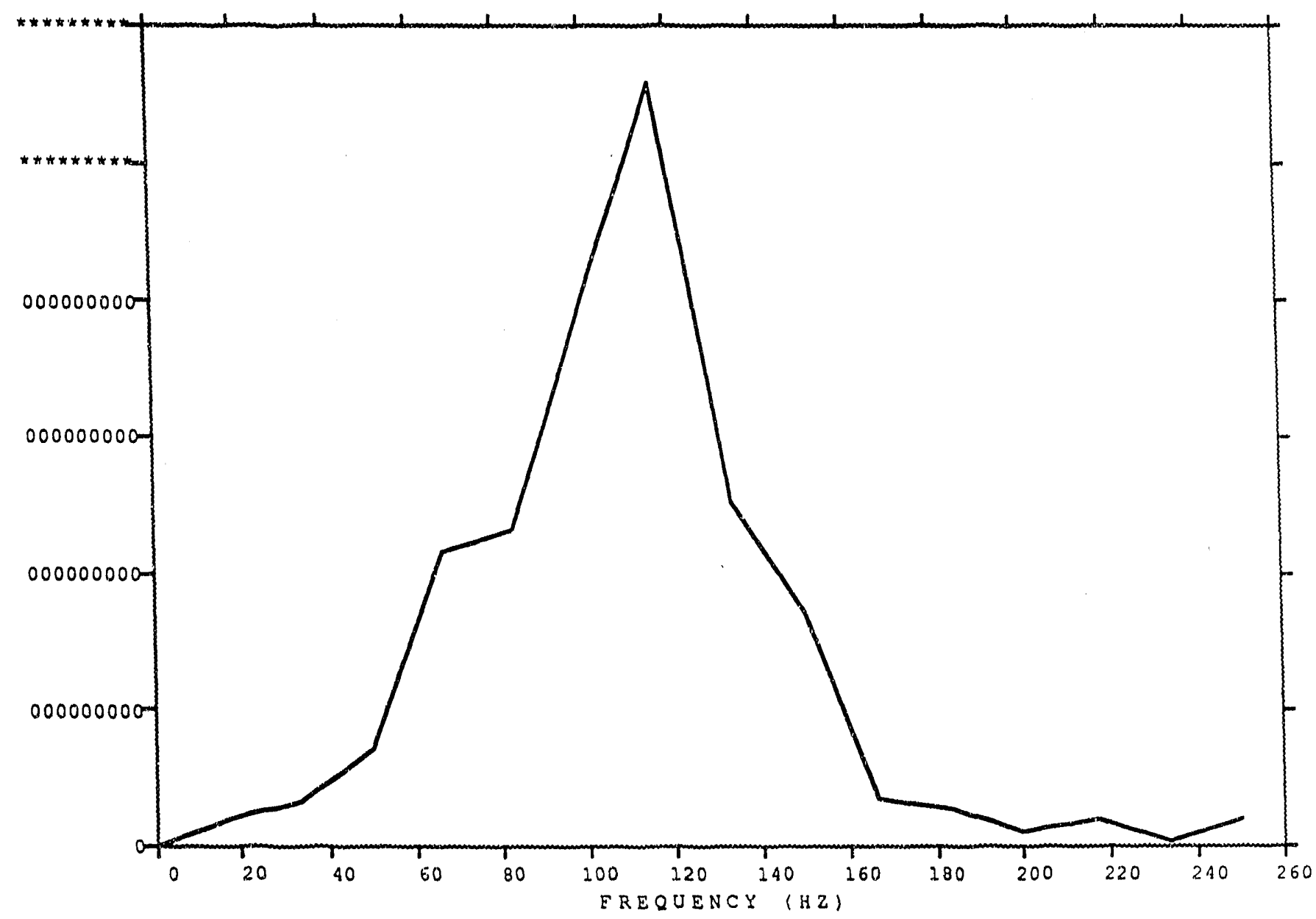

Figure 7. Spectrum of shear wave (SV) wavelet on a vertical component geophone when the Sandia source was at the $1400 \mathrm{ft}$. level. The receiver is the upper most sonde (1300 ft.) in the Halliburton array. Total path length is $1900 \mathrm{ft}$. 

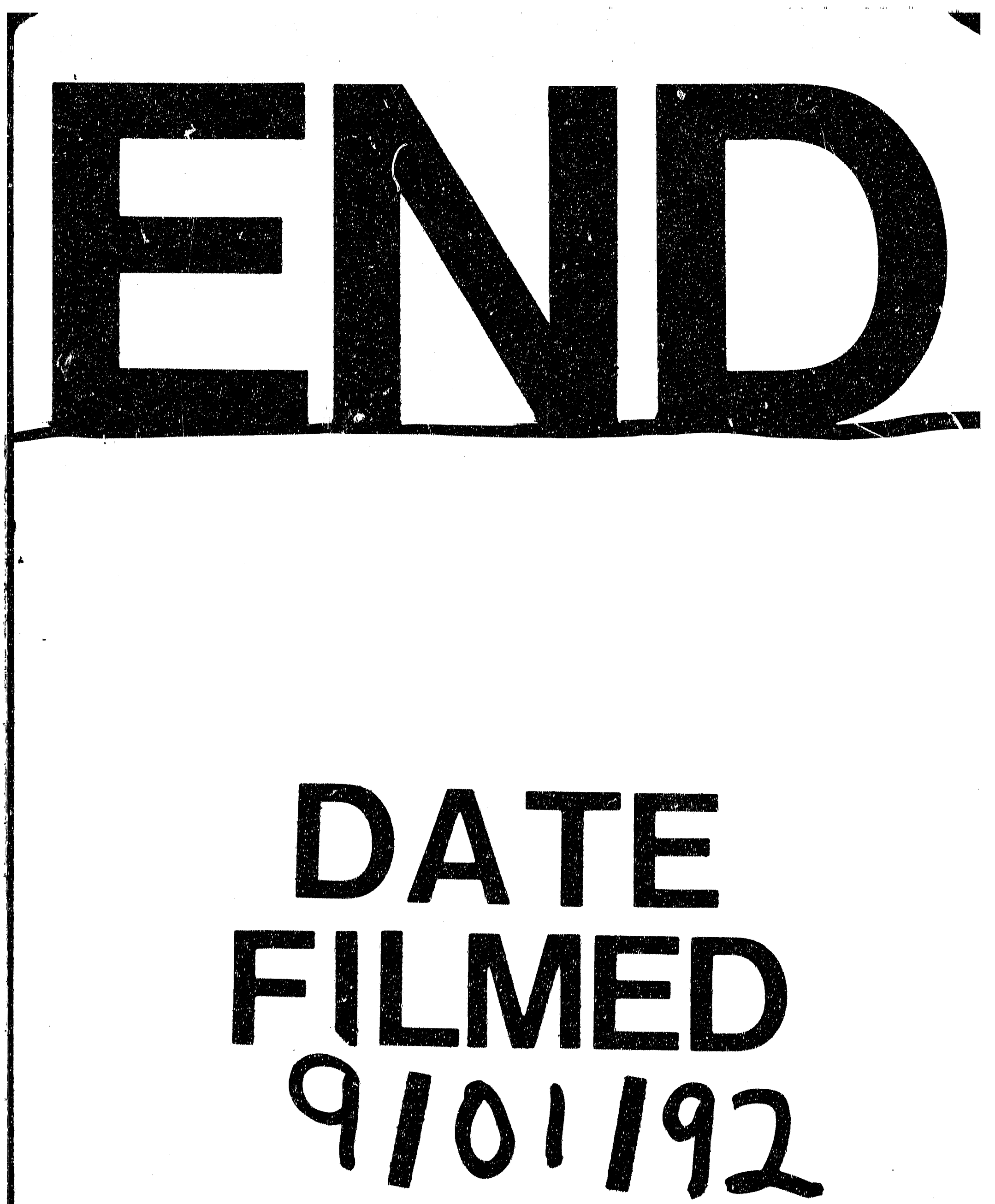
